\title{
Jet Soot: Chemical and Structural Characterization via XPS and HRTEM
}

\author{
Randy L. Vander Wal* and Victoria M. Bryg**
}

*Penn State University, Dept. of Energy and Mineral Engineering, The EMS Energy Institute and The Penn State Institutes of Energy and the Environment, University Park PA 16802

** The Universities Space Research Association (USRA) at NASA-Glenn Research Center, 21000 Brookpark Rd. Cleveland, OH 44135

Soot particles in the atmosphere have been shown to cause pulmonary and cardiovascular disease as well as contributing to global warming (1). Soot surface chemistry may also determine whether it can serve as cloud nuclei. In so doing, soot contributes to aerosol formation and radiative forcing of the atmospheric radiative balance (2). Nanostructure determines overall soot reactivity and participation in heterogeneous reactions. Together, nanostructure and surface chemistry are properties used to identify the oxidation state, elemental composition and functional groups of jet engine particulate soots.

X-ray photoelectron spectroscopy (XPS) provides a means for probing soot nanostructure and surface chemistry. It provides not only information about the atomic composition of a sample but also information about the structure and oxidation states of the constituent elements. As applied to carbon, XPS spectra distinguish a variety of surface oxygen species including phenolic, carbonyl, and carboxylic acid groups in addition to carbon fine structure. Components of the $\mathrm{C} 1 \mathrm{~s}$ peak also include $\mathrm{C}-\mathrm{C} \mathrm{sp}, \mathrm{C}-\mathrm{C} \mathrm{sp}{ }^{2}$, and $\mathrm{C}-\mathrm{C} \mathrm{sp}{ }^{3}$ structures. These groups correspond to different bonding states of carbon produced during its formation. Significant spectral peak intensity differences exist between samples from different engines and conditions. Additionally distinct elemental surface compositions are derived for these varied soots. In totality, these measures produce a recognizable chemical and physical fingerprint of the soot. Results will be presented for XPS analysis applied to soot collected from various jet engines at various power capacities.

Just as the oxygen groups present a unique source signature for many types of soot so too does the carbon $\mathrm{sp}^{2}$ and defective $\mathrm{sp}^{2}$ components (3). The specific fractional content of graphitic and non-graphitic structures can be observed and characterized by XPS. Carbon lamellae structure in soots can be further characterized in terms of fullerenic structures, degrees of parallel (graphitic) structure, or of chaotic (intertwined) structures. These along with carbon lamellae length measurements as derived from analysis of brightfield HRTEM images can provide complementary carbon nanostructural characterization.

(1) http://www.epa/gov/region07/programs/artd/air/quality/pmhealth.htm

(2) V. Ramanathan, P. J. Crutzen, J. T. Kiehl, D. Rosenfeld, "Aerosols, Climate and the Hydrological cycle", Science 294 (2001) 2119-2124.

(3) Vander Wal, R. L., and Mueller, C. J. (2006) Initial Investigation of Effects of Fuel Oxygenation on Nanostructure of Soot from a Direct-injection Diesel Engine,

Energy and Fuels, 20, pp. :2364-2369. 


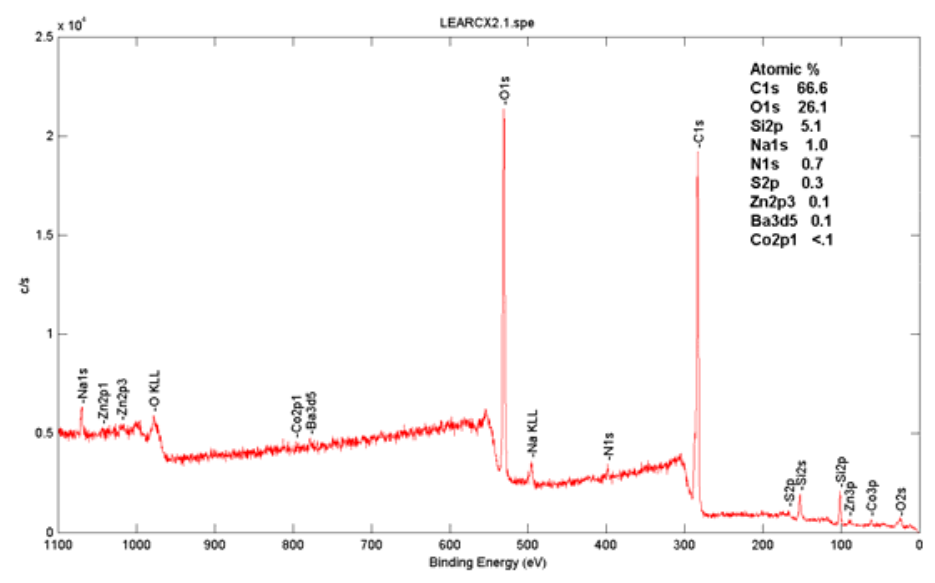

Figure 1. Elemental surface composition can be characterized by XPS.

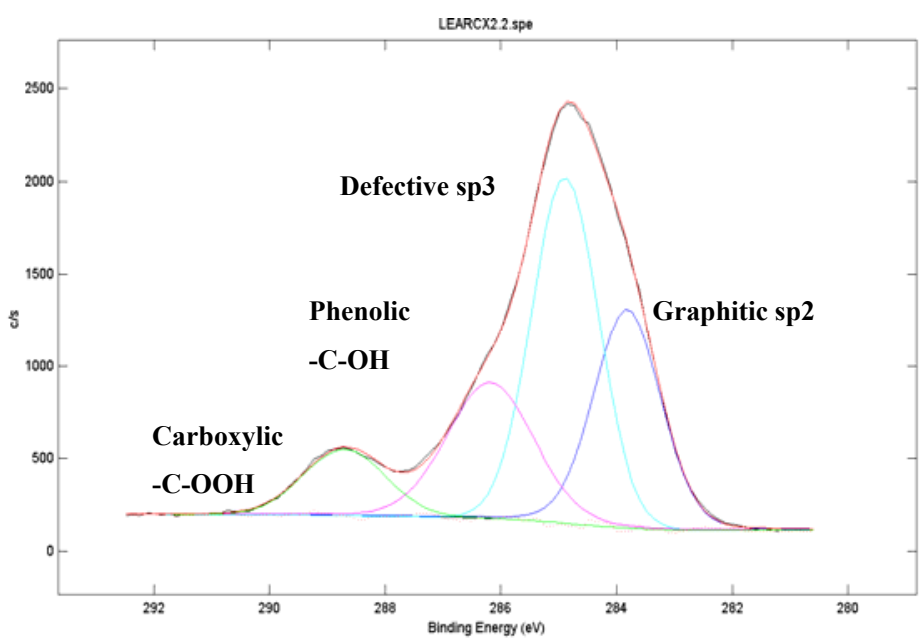

Figure 2. Soot surface chemistry showing oxidation peaks.

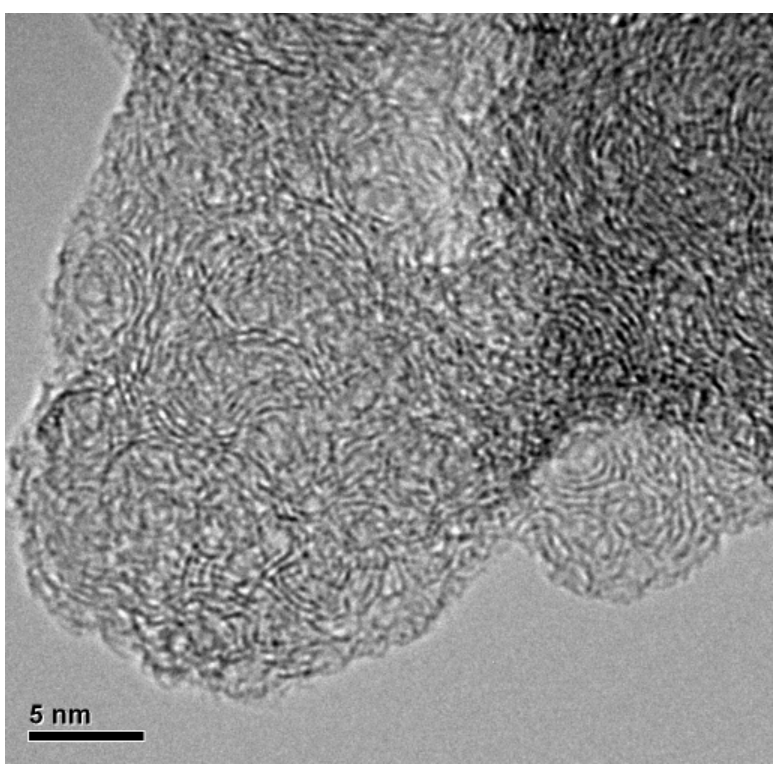

Figure 3. HRTEM of carbon particle with multi-nucleate structure and moderate fringe length and curvature. 